\title{
Genoketides A1 and A2, New Octaketides and Biosynthetic Intermediates of Chrysophanol Produced by Streptomyces sp. AK $671^{\dagger}$
}

\author{
Hans-Peter Fiedler, Anke Dieter, Tobias A. M. Gulder, Inga Kajahn, Andreas Hamm, \\ Ros Brown, Amanda L. Jones, Michael Goodfellow, Werner E. G. Müller, \\ Gerhard Bringmann
}

Received: April 18, 2008 / Accepted: July 17, 2008

(C) Japan Antibiotics Research Association

\begin{abstract}
The new aromatic polyketides genoketide A1, genoketide A2 and prechrysophanol glucuronide are biosynthetic intermediates of the octaketide chrysophanol. They were isolated from the alkaliphilic strain Streptomyces sp. AK 671 together with the new metabolite chrysophanol glucuronide. The structures of the compounds were elucidated by mass spectrometry and NMR methods. Genoketide A2 exhibited a slight and prechrysophanol glucuronide a more pronounced inhibition of the proliferation of L5178y lymphoma cells.
\end{abstract}

Keywords Streptomyces, octaketides, chrysophanol, fermentation, structure elucidation, antitumor activity

\section{Introduction}

Alkaliphilic and alkalitolerant streptomycetes isolated from various alkaline soils in Durham and Northumberland, UK, were screened for novel secondary metabolites by HPLC- diode array analysis (HPLC-DAD). These organisms are proving to be a rich source of interesting bioactive compounds, as exemplified by lactonamycin $\mathrm{Z}$ and pyrocoll, secondary metabolites with antibiotic and antitumor properties $[2,3]$.

Strain AK 671, which was isolated from a pine wood soil at Hamsterley Forest, gained our special interest because of the appearance of a multitude of metabolites in its culture filtrate. Some of the UV-visible spectra were similar to aromatic polyketides, but none of them corresponded to the reference compounds stored in our HPLC-UV-Vis database [4]. Two new naphthalene diketones, named genoketide A1 (1) and A2 (2), were isolated from the culture filtrate and their structures determined. The bicyclic diketone $\mathbf{1}$ was assumed to be an intermediate in the biosynthesis of the octaketide chrysophanol in plants and fungi [5 8], but has never been isolated because of the fast turnover of polyketo intermediates and their restricted diffusion from the polyketide synthase. In this study we describe the discovery of the postulated precursors genoketide A1 (1) and A2 (2)
H.-P. Fiedler (Corresponding author), A. Dieter: Mikrobiologisches Institut, Universität Tübingen, Auf der Morgenstelle 28, 72076 Tübingen, Germany,

E-mail: hans-peter.fiedler@uni-tuebingen.de

M. Goodfellow, R. Brown, A. L. Jones: School of Biology, University of Newcastle, Newcastle upon Tyne NE1 7RU, UK

G. Bringmann (Corresponding author), T. A. M. Gulder, I. Kajahn, A. Hamm: Institut für Organische Chemie, Am Hubland, 97074 Würzburg, Germany,

E-mail: bringmann@chemie.uni-wuerzburg.de
W. E. G. Müller: Abteilung Angewandte Molekularbiologie, Institut für Physiologische Chemie, Duesbergweg 6, 55099 Mainz, Germany

${ }^{\dagger}$ Art. No. 46 in 'Biosynthetic Capacities of Actinomycetes'. Art. No. 45: see ref. 1 


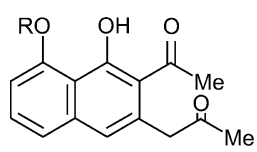

1,2

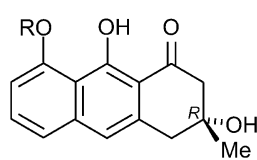

3,4
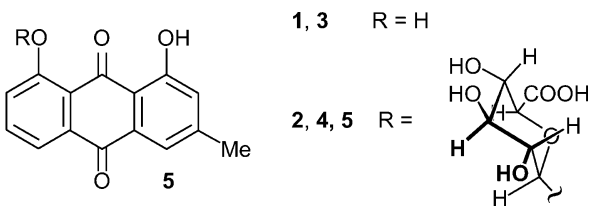

Fig. 1 Structures of genoketides A1 (1) and A2 (2), prechrysophanol (3), prechrysophanol glucuronide (4), and chrysophanol glucuronide (5)

together with prechrysophanol (3) and its glucuronide 4, which is the first report on the occurrence in nature, and chrysophanol glucuronide (5) during our HPLC-DAD screening program. The paper deals with the fermentation, isolation, structural elucidation and biological activities of the isolated metabolites. Our investigations on the biosynthetic pathway of $\mathbf{1}$ and $\mathbf{2}$ and its direct aldol addition product 4 leading to the end-product chrysophanol glucuronide (5), which was confirmed by feeding experiments with $1,2-{ }^{13} \mathrm{C}$-labeled acetate, will be reported in a forthcoming publication.

\section{Materials and Methods}

\section{Producing Organism and Taxonomy}

Streptomyces strain AK 671 was isolated from a pine forest soil collected at Hamsterley Forest, County Durham, UK. It was examined for genotypic and phenotypic properties known to be of value in streptomycete systematics [9].

\section{Fermentation and Isolation}

Batch fermentations of strain AK 671 were carried out in a 10-liter stirred tank fermentor (Biostat E, B. Braun, Melsungen, Germany) using a complex medium that consisted of starch soluble $10 \mathrm{~g}$, glucose $10 \mathrm{~g}$, glycerol $10 \mathrm{~g}$, Bacto peptone $5.0 \mathrm{~g}$, corn steep powder (Marcor) $2.5 \mathrm{~g}$, yeast extract (Ohly Kat, Deutsche Hefewerke) $2.0 \mathrm{~g}, \mathrm{NaCl}$ $1.0 \mathrm{~g}$ in 1.0 liter tap water. The fermentor was inoculated with 5 vol. $\%$ of shake cultures, grown in $500-\mathrm{ml}$ Erlenmeyer flasks of the same medium with one baffle for 48 hours on a rotary shaker at $120 \mathrm{rpm}$ and $27^{\circ} \mathrm{C}$. The fermentation was carried out at $27^{\circ} \mathrm{C}$ with an aeration rate of $0.5 \mathrm{vvm}$ and an agitation of $250 \mathrm{rpm}$. The $\mathrm{pH}$ of the culture was kept constant at $\mathrm{pH} 8.0$ throughout cultivation. The incubation time depended on the sought metabolites.

Hyphlo Super-cel $(2.0 \%)$ was added to the fermentation broth; the broth was separated by multiple sheet filtration into culture filtrate and mycelium, and the latter was discarded. The culture filtrate ( 8.0 liters) was adjusted to $\mathrm{pH} 2.0(1.0 \mathrm{M} \mathrm{HCl})$ and extracted three times with EtOAc for isolation of $\mathbf{1}$ and $\mathbf{2}$. The organic extracts were combined and concentrated in vacuo to dryness. The crude product $(3.0 \mathrm{~g})$ was dissolved in $\mathrm{CH}_{2} \mathrm{Cl}_{2}$ and added to a diol-modified silica gel column $(45 \times 2.6 \mathrm{~cm}$; LiChroprep DIOL, $40 \sim 63 \mu \mathrm{m}$; E. Merck), and separation accomplished by a linear gradient from $\mathrm{CH}_{2} \mathrm{Cl}_{2}$ to $\mathrm{CH}_{2} \mathrm{Cl}_{2}-\mathrm{MeOH}(7: 3)$ within 4 hours at a flow rate of $5.0 \mathrm{ml} /$ minute. Fractions containing the separated compounds $\mathbf{1}$ and $\mathbf{2}$ were purified by Toyopearl HW-40F chromatography $(90 \times 2.5 \mathrm{~cm}$; Tosoh Biosep) using $\mathrm{MeOH}$ as eluent. In order to obtain pure $\mathbf{1}$ and 2, each fraction was separated by preparative RPHPLC (Nucleosil-100 C-18, $10 \mu \mathrm{m}, \quad 250 \times 16 \mathrm{~mm}$; Macherey \& Nagel) using $0.5 \% \mathrm{HCOOH}-\mathrm{MeOH}$ as eluent and a linear gradient from 20 to $60 \% \mathrm{MeOH}$ over 20 minutes at a flow rate of $24 \mathrm{ml} /$ minute.

For isolation of 3, $\mathbf{4}$ and $\mathbf{5}$, the culture filtrate (7.0 liters) was applied to an Amberlite XAD-16 column (resin volume $700 \mathrm{ml}$ ); the resin was washed with $\mathrm{H}_{2} \mathrm{O} .4$ was desorbed from the resin with $\mathrm{H}_{2} \mathrm{O}-\mathrm{MeOH}(60: 40), 5$ with $\mathrm{H}_{2} \mathrm{O}-\mathrm{MeOH}(40: 60)$, and 3 with pure $\mathrm{MeOH}$. 3, 4 and 5 containing eluates were concentrated separately in vacuo to the aqueous residues and adjusted to $\mathrm{pH} 2.0(1.0 \mathrm{M} \mathrm{HCl}) .3$ and $\mathbf{4}$ were extracted separately twice with $n-\mathrm{BuOH}$, and $\mathbf{5}$ extracted twice with EtOAc. The extracts were concentrated to dryness, dissolved in a small volume of $\mathrm{MeOH}$ and purified by Sephadex LH-20 chromatography $(90 \times 2.5 \mathrm{~cm}$; Amersham) using $\mathrm{MeOH}$ as eluent.

\section{HPLC-DAD Analysis}

The chromatographic system consisted of an HP 1090M liquid chromatograph equipped with a diode-array detector and an HP Kayak XM 600 ChemStation (Agilent Technologies). Multiple wavelength monitoring was performed at 210, 230, 260,280,310, 360, 435 and $500 \mathrm{~nm}$, and UV-visible spectra measured from 200 to $600 \mathrm{~nm}$. A sample of the fermentation broth was centrifuged, and the supernatant injected onto an HPLC column $(125 \times 4.6 \mathrm{~mm})$ fitted with a guard column $(20 \times 4.6 \mathrm{~mm})$ filled with $5-\mu \mathrm{m}$ Nucleosil-100 C-18 (Maisch). The samples were analysed by linear gradient elution using $0.1 \%$ ortho-phosphoric acid as solvent $\mathrm{A}$ and $\mathrm{MeCN}$ as solvent $\mathrm{B}$ at a flow rate of $2.0 \mathrm{ml} /$ minute. The gradient was from 0 to $100 \%$ for solvent B in 15 minutes 
with a 2 -minute hold at $100 \%$ of solvent B.

\section{Structure Elucidation}

UV spectra were measured on a CARY 50 Conc UV-vis spectrophotometer (Varian) and CD spectra recorded on a J-715 spectrometer (Jasco). The optical rotation of chiral compounds was determined on a P-1020 polarimeter (Jasco) at $589 \mathrm{~nm}$. NMR experiments were carried out on either an Avance 400 or on a DMX 600 machine (both Bruker). The NMR pulse programs were taken from the standard Bruker library. Mass spectral analysis was achieved on an Agilent 1100 HPLC system in combination with an Agilent 1100SL ion trap, or, offline, on a time-offlight mass detector microTOF (Bruker).

\section{Enzymatic Cleavage of Glucuronic Acid Residues}

A catalytic amount of $\beta$-glucuronidase (Sigma, 6-8396, Type VII A (E. coli)) and $1.0 \mathrm{mg}$ of 2 were dissolved in $10 \mathrm{ml} \mathrm{H}_{2} \mathrm{O}$. The reaction mixture was stirred at $35^{\circ} \mathrm{C}$ for 6 hours and extracted with $\mathrm{CH}_{2} \mathrm{Cl}_{2}$. The respective aglycon 1 was obtained from the organic layer after removal of the solvent in vacuo, whereas D-glucuronic acid was isolated from the aqueous layer.

\section{Biological Activities}

An agar plate diffusion assay was used to determine the antibacterial and antifungal properties of the metabolites produced by strain AK 671 using Arthrobacter aurescens DSM 20166, Bacillus subtilis DSM 10, Brevibacillus brevis DSM 30, Staphylococcus aureus DSM 20231 and Streptomyces viridochromogenes Tü 57 (Gram-positive bacteria), Escherichia coli K12, Pseudomonas fluorescens DSM 50090 and Proteus mirabilis ATCC 35501 (Gramnegative bacteria). The yeasts and filamentous fungi examined were Candida albicans Tü 164, Saccharomyces cerevisiae ATCC 9080, Botrytis cinerea Tü 157 and Penicillium notatum Tü 136. Ten $\mu$ l of the samples were applied to filter paper disks (6 $\mathrm{mm}$ diameter), which were added to inoculated test plates that were incubated for 24 hours (bacteria) and 48 hours (fungi) at temperatures that ensured the optimal growth of the test organisms.

Murine leukemic lymphoblasts cells L5178y (ATCC CRL 1722) were used $[10,11]$ to establish the inhibition of tumor cell proliferation. The tumor cells were grown as described previously [12], but with the enrichment of the RPMI-1640 medium with $10 \%$ fetal calf serum. All of the cells were kept in a humidified atmosphere of $5.0 \% \mathrm{CO}_{2}$ and $95 \%$ air. Cell viability was assessed by using the methylthiazolyldiphenyl-tetrazolium bromide (MTT) method as previously described [13]. The cells were used to seed 96-well plates at a density of $10 \times 10^{3}$ cells per well with or without the compound. After 72 hours, the plates were analysed on a microplate reader (model 450; Bio-Rad) at a test wavelength of $595 \mathrm{~nm}$. Ten parallel assays were performed for each concentration of the respective compounds. The $\mathrm{ED}_{50}$ concentrations were determined by logit regression [14].

\section{Results}

\section{Taxonomy of the Producing Strain}

The presence of LL-diaminopimelic acid in whole-organism hydrolysates [15] together with colonial and morphological properties [16] indicated that strain AK 671 is a member of the genus Streptomyces. The strain produces straight chains of smooth surfaced spores. When the almost complete $16 \mathrm{~S}$ rRNA gene sequence of the isolate was compared with corresponding sequences of representatives of the genus Streptomyces it was found to form a distinct phyletic line in the Streptomyces 16S rRNA gene tree. It was most closely, albeit only loosely, associated with the type strain of Streptomyces auvicolor (98.6\% 16S rRNA gene similarity). It is evident from these results that isolate $\mathrm{AK} 671$ has properties consistent with it being assigned to a new Streptomyces species.

\section{Screening, Fermentation and Isolation}

Samples of culture filtrates from shake cultures of Streptomyces strain AK 671 were screened by using our HPLC-DAD method. Several major peaks were monitored in the HPLC chromatogram, and were found to be strongly dependent on the cultivation time of strain AK 671. Compounds $\mathbf{1}$ and $\mathbf{2}$ with retention times of 7.9 and 5.9 minutes, respectively, were the dominant metabolites at an early stage of fermentation (Fig. 2a), whereas compounds 4 (retention time 5.5 minutes) and $\mathbf{5}$ (retention time 7.2 minutes) were accumulated during the ongoing fermentation process (Fig. 2b). The lack of UV-visible spectral identity among the 867 reference compounds stored in our HPLC-UV-Vis database prompted us to undertake more detailed investigations on the production behaviour of the strain. Some of the produced metabolites were detected solely in the culture filtrate or in EtOAc

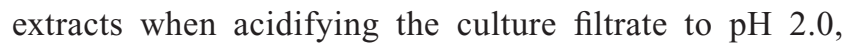
thereby indicating the precence of strong acidic lipophilic compounds (2, 4 and 5).

Strain AK 671 showed alkaliphilic growth properties resulting in a $20 \%$ increased biomass production when the $\mathrm{pH}$ was kept constant at 8.0 during fermentation compared to growth at $\mathrm{pH}$ 7.0. Batch fermentations were carried out in a 10-liter fermentor using a complex medium; the $\mathrm{pH}$ of 

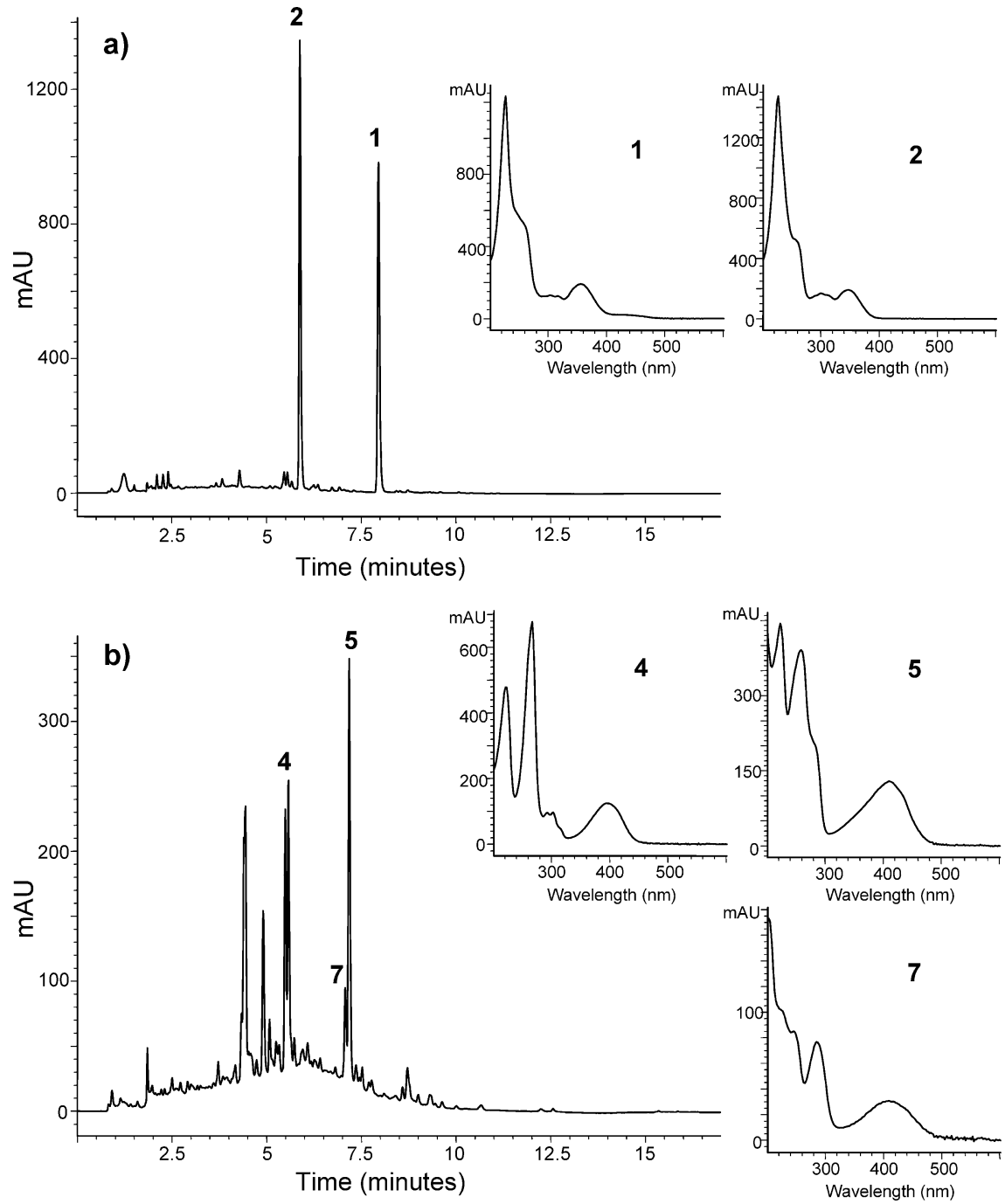

Fig. 2 HPLC analysis of a culture filtrate of Streptomyces sp. AK 671 at (a) fermentation time of 48 hours, and (b) fermentation time of 135 hours, monitored at $230 \mathrm{~nm}$, and UV-visible spectra of genoketides A1 (1; 7.9 minutes) and A2 (2; 5.9 minutes), of prechrysophanol glucuronide (4; 5.5 minutes), chrysophanol glucuronide $(\mathbf{5} ; 7.2$ minutes), and juglomycin $\mathrm{F}$ (7; 7.05 minutes).

the culture was kept constant at $\mathrm{pH}$ 8.0. The production of the aglycon genoketide A1 (1) started at 19 hours after inoculation and reached a concentration of $390 \mathrm{mg} / \mathrm{liter}$ at 43 hours. The conversion from 1 into the glucuronated genoketide A2 (2) occurred between 24 and 64 hours of incubation and reached a maximal concentration of $600 \mathrm{mg} /$ liter after 64 hours. In the course of the fermentation process, $\mathbf{2}$ was completely converted to prechrysophanol glucuronide (4) after 76 hours of incubation reaching a concentration of $600 \mathrm{mg} / \mathrm{liter}$ of $\mathbf{4}$, followed by the conversion of $\mathbf{4}$ into chrysophanol glucuronide (5) between 76 and 236 hours of fermentation. 5 reached a final amount of $355 \mathrm{mg} /$ liter, whereas the aglycon prechrysophanol (3) resulted in a maximal amount of $63 \mathrm{mg} /$ liter after a fermentation time of 144 hours. The course of the conversion of genoketide intermediates via prechrysophanol glucuronide to the end-product chrysophanol glucuronide (5) is shown in Fig. 3.

For isolation of the precursors $\mathbf{1}$ and $\mathbf{2}$, the fermentation was terminated after incubation for 42 hours, and the metabolites isolated from the culture filtrate by extraction with EtOAc and purified by subsequent chromatography on diol-modified silica gel, Toyopearl HW-40F and preparative reversed-phase HPLC. 1 and $\mathbf{2}$ were obtained as beige powders after lyophilisation. The fermentation was extended to an incubation time of about 160 hours for the isolation of $\mathbf{3}, \mathbf{4}$ and $\mathbf{5}$. The metabolites were isolated from the culture filtrate by Amberlite XAD-16 chromatography 


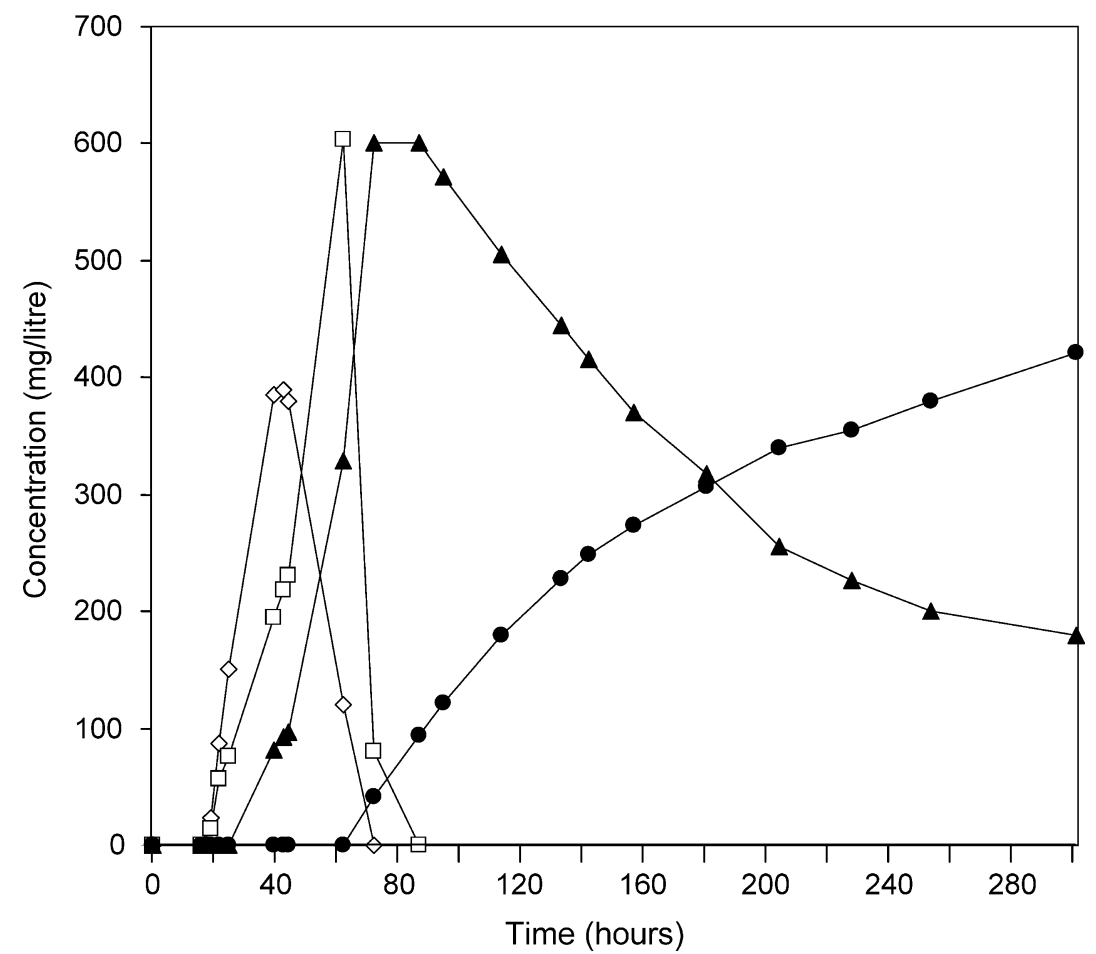

Fig. 3 Time course of the conversion of the intermediates genoketides A1 (1; $\diamond)$ and A2 (2; $\square)$ and of prechrysophanol glucuronide $(\mathbf{4} ; \mathbf{\Delta})$ to the end-product chrysophanol glucuronide $(\mathbf{5} ; \mathbf{\bullet})$ during fermentation.

and purified by extraction and Sephadex LH-20 chromatography. Compounds 3, 4 and $\mathbf{5}$ were obtained as yellow powders after lyophilisation.

\section{Structure Elucidation}

Genoketide A2 (2) showed a molecular weight of 434 Dalton $\left([\mathrm{M}+\mathrm{H}]^{+} m / z 435\right)$ in its ESI mass spectrum. In the EI and DCI mass spectral analysis only a fragment with $\mathrm{m} / \mathrm{z}$ 240 was detectable. The molecular formular $\mathrm{C}_{15} \mathrm{H}_{12} \mathrm{O}_{3}$ of this partial structure was deduced by high-resolution mass spectrometry. ${ }^{1} \mathrm{H}-\mathrm{NMR}$ investigations indicated the presence of a glucuronide, three neighbouring and one isolated aromatic proton, and a methylene and two methyl groups. In the ${ }^{13} \mathrm{C}$-NMR spectrum the signals for the sugar moiety, ten aromatic carbons, two carbonyl functions, two methyl groups and one methylene unit were visible (Table 1).

The structure of the naphthalene portion and the constitution of the glucuronic acid moiety was established in a series of HMBC experiments (Fig. 4a). The positions of the substituents of the naphthalene core were evident from interactions of $\mathrm{CH}_{3}-10$ with $\mathrm{C}-2$, of $\mathrm{CH}_{2}-11$ with $\mathrm{C}-2$, $\mathrm{C}-3$, and $\mathrm{C}-4$, of the anomeric proton $\mathrm{H}-1^{\prime}$ with $\mathrm{C}-8$, and of the free hydroxy group with $\mathrm{C}-1$. This constitution was validated by ROESY interactions (Fig. 4b). Furthermore,
Table 1 NMR data of 2 in $\mathrm{Me}_{2} \mathrm{CO}-d_{6}\left({ }^{1} \mathrm{H}: 600 \mathrm{MHz} ;{ }^{13} \mathrm{C}\right.$ : $150 \mathrm{MHz}$ )

\begin{tabular}{crl}
\hline No. & $\delta\left({ }^{13} \mathrm{C}\right)[\mathrm{ppm}]$ & $\delta\left({ }^{1} \mathrm{H}\right)[\mathrm{ppm}](\mathrm{J} \mathrm{in} \mathrm{Hz})$ \\
\hline 1 & 153.5 & - \\
2 & 125.5 & - \\
3 & 133.0 & - \\
4 & 122.1 & $7.18 \mathrm{~s}$ \\
$4 \mathrm{a}$ & 137.4 & - \\
5 & 124.0 & $7.50 \mathrm{~d}(7.9)$ \\
6 & 128.5 & $7.44 \mathrm{dd}(7.7,7.9)$ \\
7 & 112.2 & $7.39 \mathrm{~d}(7.7)$ \\
8 & 155.6 & - \\
$8 \mathrm{a}$ & 115.4 & - \\
9 & 204.7 & - \\
10 & 32.0 & $2.54 \mathrm{~s}$ \\
11 & 48.4 & $3.93 \mathrm{~d}(2.4)$ \\
12 & 205.4 & \\
13 & 29.9 & $2.14 \mathrm{~s}$ \\
$1^{\prime}$ & 103.9 & $5.40 \mathrm{~d}(7.5)$ \\
$2^{\prime}$ & 74.2 & $3.77 \mathrm{dd}(8.1,8.6)$ \\
$3^{\prime}$ & 76.9 & $3.71 \mathrm{dd}(8.7,8.8)$ \\
$4^{\prime}$ & 72.5 & $3.82 \mathrm{t}(9.2)$ \\
$5^{\prime}$ & 76.3 & $4.25 \mathrm{~d}(9.5)$ \\
$6^{\prime}$ & 169.9 & - \\
\hline
\end{tabular}


A

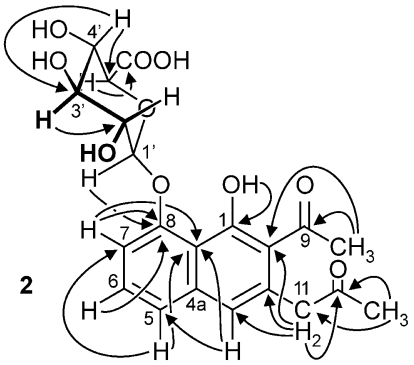

B

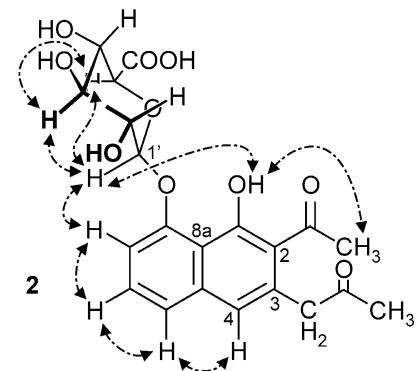

Fig. 4 Important $\operatorname{HMBC}(\mathrm{A}, \frown$ ) and $\operatorname{ROESY}(\mathrm{B}, \cdots \cdot)$ interactions used for the structural elucidation of genoketide $A 2(\mathbf{2})$.

Table 2 NMR data of 4 and $\mathbf{5}$ in $\mathrm{MeOH}-d_{4}\left({ }^{1} \mathrm{H}: 400 \mathrm{MHz} ;{ }^{13} \mathrm{C}: 100 \mathrm{MHz}\right)$

\begin{tabular}{|c|c|c|c|c|}
\hline \multirow{2}{*}{ No. } & \multicolumn{2}{|r|}{4} & \multicolumn{2}{|r|}{5} \\
\hline & $\delta\left({ }^{13} \mathrm{C}\right)[\mathrm{ppm}]$ & $\delta\left({ }^{1} \mathrm{H}\right)[\mathrm{ppm}](\mathrm{J}$ in $\mathrm{Hz})$ & $\delta\left({ }^{13} \mathrm{C}\right)[\mathrm{ppm}]$ & $\delta\left({ }^{1} \mathrm{H}\right)$ [ppm] $(\mathrm{J}$ in $\mathrm{Hz})$ \\
\hline 1 & 205.9 & - & 163.9 & - \\
\hline 2 & 52.9 & $\begin{array}{l}2.81 \mathrm{~d}(15.9) \\
2.88 \mathrm{~d}(16.1)\end{array}$ & 125.5 & $7.12 \mathrm{~s}$ \\
\hline 3 & 71.4 & - & 149.7 & - \\
\hline 4 & 44.2 & $\begin{array}{l}3.14 d(17.2) \\
3.07 d(17.2)\end{array}$ & 121.1 & $7.56 \mathrm{~s}$ \\
\hline $4 a$ & 138.3 & - & 134.1 & - \\
\hline 5 & 123.5 & $7.40 \mathrm{~d}(7.6)$ & 123.3 & $8.00 \mathrm{~d}(7.7)$ \\
\hline 6 & 132.2 & 7.51 t (8.0) & 137.1 & $7.80 \mathrm{dd}(7.7,8.3)$ \\
\hline 7 & 113.7 & $7.23 \mathrm{~d}(7.8)$ & 125.2 & $7.73 d(8.3)$ \\
\hline 8 & 158.6 & - & 159.7 & - \\
\hline $8 a$ & 116.8 & - & 123.3 & - \\
\hline 9 & 165.1 & - & 189.9 & - \\
\hline $9 a$ & 112.8 & - & 115.5 & - \\
\hline 10 & 119.5 & $7.11 \mathrm{~s}$ & 183.8 & - \\
\hline $10 a$ & 141.6 & & 136.8 & - \\
\hline $1^{\prime}$ & 104.7 & $5.02 d(7.6)$ & 103.5 & $5.18 d(7.6)$ \\
\hline $2^{\prime}$ & 75.1 & $3.72 \mathrm{dd}(7.9,9.1)$ & 74.7 & $3.75 \mathrm{dd}(7.6,9.1)$ \\
\hline $3^{\prime}$ & 77.0 & $3.56 \mathrm{t}(9.1)$ & 77.2 & $3.58 \mathrm{dd}(8.9,9.1)$ \\
\hline $4^{\prime}$ & 73.1 & 3.70 t (9.9) & 73.1 & $3.69 \mathrm{dd}(8.9,9.7)$ \\
\hline $5^{\prime}$ & 77.1 & $4.03 \mathrm{~d}(9.7)$ & 76.9 & $4.05 d(9.7)$ \\
\hline $6^{\prime}$ & 172.5 & - & 172.9 & - \\
\hline Me-3 & 22.1 & $1.40 \mathrm{~s}$ & 22.2 & $2.44 \mathrm{~s}$ \\
\hline
\end{tabular}

the relative configuration of all of the stereogenic centers of the sugar part was deducible from the ROESY experiment. The chemical shift of $1^{\prime}-\mathrm{H}(5.40 \mathrm{ppm})$ and its coupling constant with $2^{\prime}-\mathrm{H}(J=7.5 \mathrm{~Hz})$ showed the anomeric center to be $\beta$-configured. Enzymatic hydrolysis using a $\beta$ glucuronidase gave free glucuronic acid, which was assigned to be the D-enantiomer by its optical rotation. The aglycon of genoketide A2 (2) was found to be fully identical with genoketide A1 (1) in HPLC coelution experiments. The spectroscopic and physical data of 1 was in full agreement with the published data of the synthetic analog [7].

The molecular formula $\mathrm{C}_{21} \mathrm{H}_{22} \mathrm{O}_{10}$ of prechrysophanol glucuronide (4) was established by high-resolution ESI mass spectroscopy $\left([\mathrm{M}-\mathrm{H}]^{-} m / z\right.$ 433.1159). In the ${ }^{1} \mathrm{H}-$ NMR spectrum of $\mathbf{4}$ an ABC spin system of three aromatic protons and the signals of an isolated aromatic proton was found, and, in addition, two diastereotopic aliphatic 
methylene units, one aliphatic methyl group and the same sugar moiety as in genoketide A2 (2). In the ${ }^{13} \mathrm{C}-\mathrm{NMR}$ spectrum an additional keto group, two hetero-atom substituted $s p^{2}$, four quarternary carbon atoms, and an aliphatic tertiary alcohol were detected (Table 2).

The presence of the two methylene units and the tertiary alcohol function attached to a presumably identical naphthalene moiety bearing a glucuronic acid residue as in 2 was indicative of a cyclization of genoketide A2 (2) to give a third ring system annelated to the naphthalene core. This assumption was unambiguously confirmed by HMBC-, COSY-, and NOESY interactions as depicted in Fig. 5.

Compound 4 was thus identified as the new 8-Oglucuronidated derivative of the known natural product prechrysophanol [8]. As for genoketide A2 (2), the Dglucuronic acid residue was stereochemically characterized after its enzymatic cleavage by analysis of its optical rotation. The aglycon of $\mathbf{4}$, prechrysophanol, was completely identical with the likewise isolated-albeit in very low quantities - secondary metabolite 3 (Fig. 6). The stereogenic center at $\mathrm{C}-3$ was shown to be $R$-configured by comparison of the optical rotation of $\mathbf{3}$ as isolated from AK $671\left([\alpha]_{\mathrm{D}}^{20}=-43^{\circ}\right)$, with the data published for $(R)$ prechrysophanol from Aloe graminicola $\left([\alpha]_{\mathrm{D}}^{20}=-45^{\circ}\right)[8]$.

The molecular formula $\mathrm{C}_{21} \mathrm{H}_{18} \mathrm{O}_{10}$ of compound $\mathbf{5}$ was deduced from high-resolution ESI mass spectroscopy $\left([\mathrm{M}-2 \mathrm{H}+\mathrm{Na}]^{-} \mathrm{m} / z\right.$ 451.0640). The characteristic UV spectrum of 5 (see Fig. 2) indicated the presence of an anthraquinone moiety. In the ${ }^{1} \mathrm{H}-\mathrm{NMR}$ the signals of an aromatic $\mathrm{ABC}$ spin system and of a glucuronic acid residue were once again observed (see Table 2). Furthermore, two isolated aromatic protons and a methyl group attached to a $s p^{2}$-carbon atom were detected. In the ${ }^{13} \mathrm{C}$-NMR spectrum of 5 two keto groups, two heteroatom-substituted $s p^{2}$ carbons and five quarternary $s p^{2}$ carbons were visible.

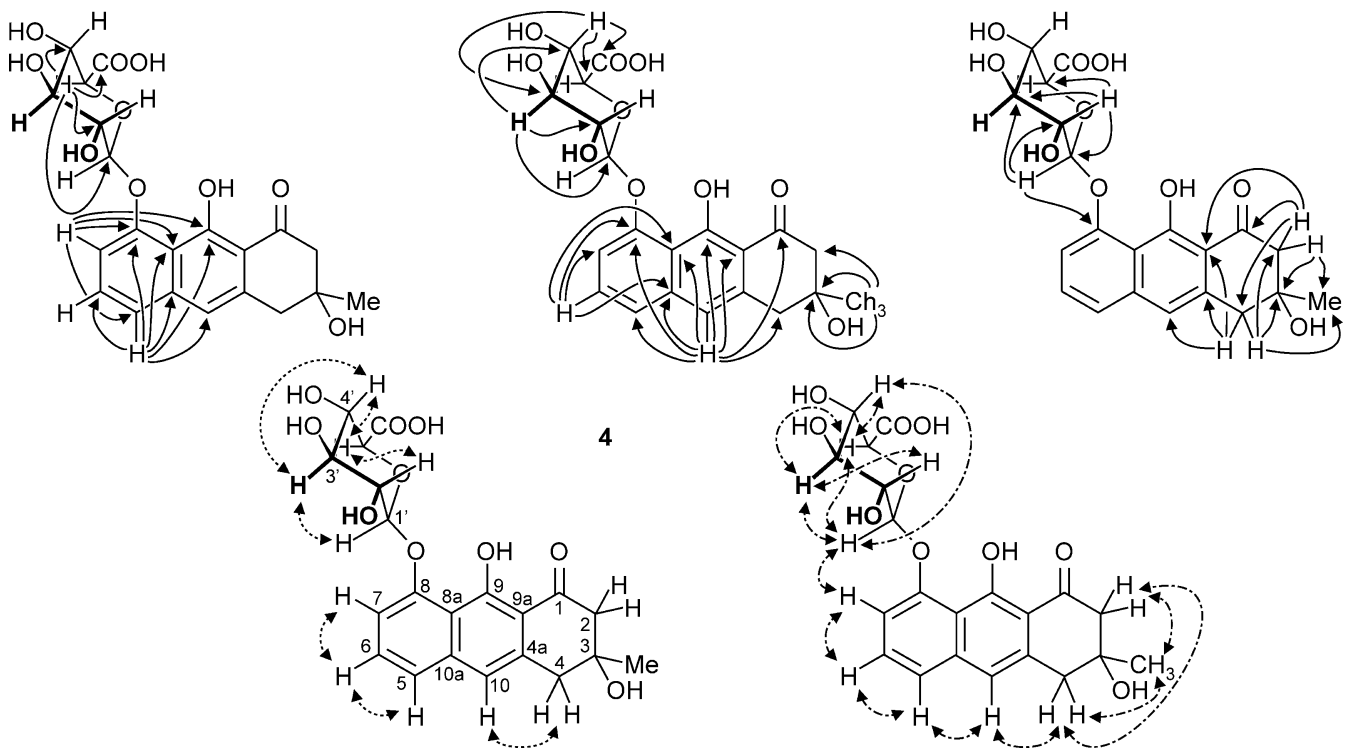

Fig. 5 Full set of $\operatorname{HMBC}(\sim), \operatorname{COSY}(\cdots)$, and $\operatorname{ROESY}(\cdots)$ interactions used for the structural elucidation of compound 4.

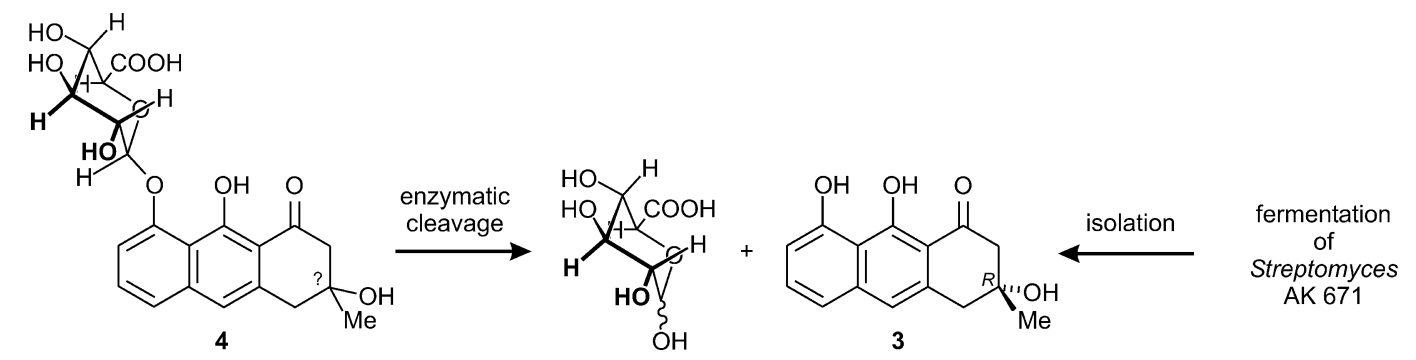

Fig. 6 Elucidation of the absolute configuration of $\mathbf{4}$ by enzymatic cleavage to give D-glucuronic acid and $(R)$ prechrysophanol (3), which also occurs as a minor metabolite in strain AK 671. 
Table 3 Physico-chemical properties of compounds 2, $\mathbf{4}$, and $\mathbf{5}$

\begin{tabular}{|c|c|c|c|}
\hline & 2 & 4 & 5 \\
\hline Appearance & Red powder & Orange solid & Yellow solid \\
\hline Molecular weight & 434 & 434 & 430 \\
\hline Molecular formula & $\mathrm{C}_{21} \mathrm{H}_{22} \mathrm{O}_{10}$ & $\mathrm{C}_{21} \mathrm{H}_{22} \mathrm{O}_{10}$ & $\mathrm{C}_{21} \mathrm{H}_{18} \mathrm{O}_{10}$ \\
\hline $\operatorname{HRMS~}(m / z)$ & $\mathrm{El}(+)$ & $\mathrm{ESI}(-)$ & $\mathrm{ESI}(-)$ \\
\hline Found & $240.0786{\text { [M-sugar }{ }^{+}}^{+}$ & $433.1159[\mathrm{M}-\mathrm{H}]^{-}$ & $451.0640[\mathrm{M}-2 \mathrm{H}+\mathrm{Na}]^{-}$ \\
\hline Calcd. & 240.0789 [M-sugar] $^{+}$ & $433.1140[\mathrm{M}-\mathrm{H}]^{-}$ & $451.0641[\mathrm{M}-2 \mathrm{H}+\mathrm{Na}]^{-}$ \\
\hline$U V(\mathrm{MeOH}) \lambda_{\max }[\mathrm{nm}]$ & $226,301,346$ & $221,267,292,302,395$ & $221,258,412$ \\
\hline$[\alpha]_{D}^{20}(\mathrm{MeOH})\left[^{\circ}\right]$ & $-14.5(c=0.106)$ & $-47.2(c=0.04)$ & $-19.3(c=0.04)$ \\
\hline $\mathrm{Mp}(\mathrm{MeOH})\left[{ }^{\circ} \mathrm{C}\right]$ & 190 & 158 & 164 \\
\hline
\end{tabular}

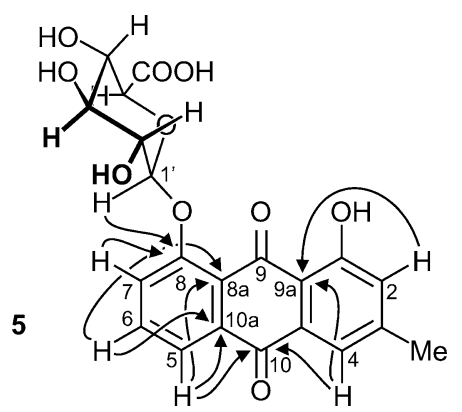

Fig. 7 Important $\mathrm{HMBC}$ correlations used for the structural elucidation of $\mathbf{5}$.

These findings, together with the mass difference of four atomic units as compared to $\mathbf{4}$, suggested that compound $\mathbf{5}$ was the new natural product chrysophanol glucuronide. This structural proposal was fully confirmed by HMBC experiments (Fig. 7), in particular those based on the interactions of $\mathrm{H}-5$ with C-8a, C-10 and C-10a, of H-6 with C-8a and C-10a, of $\mathrm{H}-7$ with $\mathrm{C}-8$ and C-8a, of the anomeric proton $\mathrm{H}-1^{\prime}$ with $\mathrm{C}-8$, of $\mathrm{H}-2$ with $\mathrm{C}-9 \mathrm{a}$, and of $\mathrm{H}-4$ with C-9a and C-10 (Fig. 3). The absolute configuration of the D-glucuronic acid substituent was again established after its enzymatic cleavage. The identity of the aglycon of $\mathbf{5}$, chrysophanol, was further checked by coelution with an authentic reference sample. Remarkably, strain AK 671 did not produce any detectable amounts of chrysophanol.

The physico-chemical properties of compounds $\mathbf{2}, \mathbf{4}$, and $\mathbf{5}$ are summarized in Table 3.

\section{Biological Activity}

Compounds 1 $\sim \mathbf{5}$ did not show antibacterial or antifungal activities against any of the tested organisms up to a concentration of $1.0 \mathrm{mg} / \mathrm{ml}$. When the effects of genoketides on the viability (cell growth) of L5178y tumor cells were examined, it was established that the cells were inhibited by prechrysophanol glucuronide (4) with an $\mathrm{ED}_{50}$ value of $6.3 \pm 0.7 \mu \mathrm{g} / \mathrm{ml}$. None of the other compounds reached the sensitivity level of an $\mathrm{ED}_{50}$ below $10 \mu \mathrm{g} / \mathrm{ml}$. An exposure of $10 \mu \mathrm{g} / \mathrm{ml}$ of genoketide A2 (2) to these cells resulted in a $15.1 \%$ reduction of cell growth, while the reduction determined for chrysophanol glucuronide (5) and juglomycin $\mathrm{F}(7)$ were $12.8 \%$ and $6.7 \%$, respectively.

\section{Discussion}

Intermediates in the biosynthetic pathway of aromatic polyketides are usually postulated as they are difficult to detect or isolate because of their high chemical reactivity and fast turnover into the end products. Exceptions are found in genetically engineered microorganisms, especially streptomycetes, which are blocked in distinct biosynthetic enzymes of the aromatic polyketides leading to a variety of shunt products, which have been summarized in a review article by David Hopwood [17]. However, wild-type strain Streptomyces AK 671 accumulated three intermediates in high amounts in the culture filtrate which were continuously transformed from one to another leading to the end product chrysophanol glucuronide (5). The intermediate $\mathbf{1}$ had previously been postulated in the biosynthesis of chrysophanol in plants and fungi $[5,7]$ but had not been detected or isolated from an organism. We designated genoketide A1 (1) as the 'Harris-Franck diketone' in honour of the outstanding synthetic and biosynthetic contributions of Thomas M. Harris and Burchard Franck on the role of this compound. The conversion of genoketide A1 (1) to prechrysophanol (3) seems to be a side-pathway of strain AK 671, resulting in relative small amounts of $\mathbf{3}$ during the fermentation process, and it is strongly dependent on the cultivation conditions. We could not find the postulated end-product of 3, which would be expected to be chrysophanol, even after 

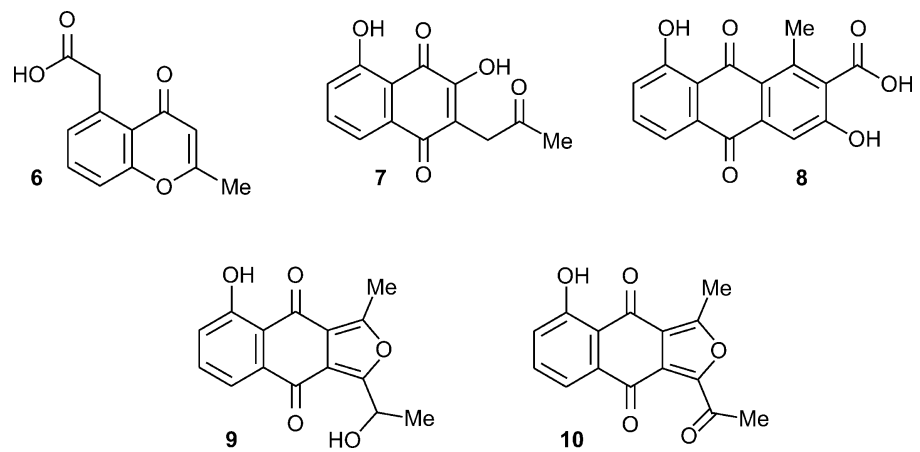

Fig. 8 Structures of 2-methyl-4-oxo-4H-chromen-5-yl-acetic acid (BSM1) (6), juglomycin F (7), 3,8-dihydroxy-1methylanthraquinone-2-carboxylic acid (DMAC) (8) and bhimamycin A (9) and B (10) produced by Streptomyces sp. AK 671.

changing cultivation media and fermentation conditions. These findings are in contrast to those in plants, where prechrysophanol (3) was identified as one of the intermediates in the biosynthesis of anthraquinones in Aloe graminicola [18]. The cyclization and aromatization of the glucuronidated derivatives $\mathbf{2}$ and $\mathbf{4}$ to finally yield $\mathbf{5}$, by contrast, seems to be the dominant biosynthetic pathway in AK 671, thereby suggesting an activating effect of the glucuronic acid moiety in the respective biosynthetic transformations.

Streptomyces strain AK 671 does not only produce genoketides A1 (1) and A2 (2), prechrysophanol (3) together with its glucuronide $\mathbf{4}$ and chrysophanol glucuronide (5), but in addition-depending on the cultivation conditions above all the cultivation mediumseveral other aromatic polyketides. These include the hexaketide BSM1 (6), which was described as a shunt product from the genetically engineered Streptomyces lividans K4-114 [19], the heptaketide juglomycin F (7), which was isolated from a wild-type Streptomyces strain [20], DMAC (8), a member of the rarely occurring $\alpha$ methyl anthraquinones [21], and the octaketides bhimamycins A (9) and B (10) [22]. The structures of these literature-known polyketide metabolites are summarized in Fig. 8.

The fermentation, isolation and structural elucidation of further metabolites produced by Streptomyces strain AK 671 that presumably belong to the family of aromatic polyketides given by their UV-visible characteristics are still under investigation and will be reported in forthcoming publications. They will give an insight into the complex flow of precursors of the biosynthetic pathway of aromatic polyketides in this highly creative streptomycete strain, which reacts dramatically to changes in fermentation conditions resulting in an altered pattern of secondary metabolites.

\section{References}

1. Paululat T, Katsifas EA, Karagouni AD, Fiedler H-P. Grecoketides A and B, new naphthoquinones from Streptomyces sp. Acta 1362. Europ J Org Chem, in press (2008)

2. Dieter A, Hamm H, Fiedler H-P, Goodfellow M, Müller WEG, Brun R, Beil W, Bringmann G. Pyrocoll, an antibiotic, antiparasitic and antitumor compound produced by a novel alkaliphilic Streptomyces strain. J Antibiot 56: 639-646 (2003)

3. Höltzel A, Dieter A, Schmid DG, Brown R, Goodfellow M, Beil W, Jung G, Fiedler H-P. Lactonamycin Z, an antibiotic and antitumor compound produced by Streptomyces sanglieri strain AK 623. J Antibiot 56: 1058-1061 (2003)

4. Fiedler H-P. Biosynthetic capacities of actinomycetes. 1. Screening for novel secondary metabolites by HPLC and UV-visible absorbance libraries. Nat Prod Lett 2: 119-128 (1993)

5. Harris TM, Webb AD, Harris CM, Wittek PJ, Murray TP. Biogenetic-type syntheses of emodin and chrysophanol. J Am Chem Soc 98: 6065-6067 (1976)

6. Webb AD, Harris TM. A biogenetically modeled synthesis of eleutherin. Tetrahedron Lett 18: 2069-2072 (1977)

7. Franck B, Stange A. Pilzinhaltstoffe, 32. Nachweis einer bicylischen Zwischenstufe der Anthrachinon-Biosynthese. Liebigs Ann Chem 1981: 2106-2116 (1981)

8. Yenesew A, Ogur JA, Duddeckt H. (R)-Prechrysophanol from Aloe graminicola. Phytochemistry 34: 1442-1444 (1993)

9. Xu C, Wang L, Cui Q, Huang Y, Liu Z, Zheng G, Goodfellow M. Neutrotolerant acidophilic Streptomyces species isolated from acidic soils in China: Streptomyces guandensis sp. nov., Streptomyces paucisporeus sp. nov., Streptomyces rubidus sp. nov. and Streptomyces yanglinensis sp. nov. Int J Syst Evol Microbiol 56: 1109-1115 (2006)

10. Müller WEG, Maidhof A, Zahn RK, Schröder HC, Gasic MJ, Heidemann D, Bernd A, Kurelec B, Eich E, Seibert G. Potent antileukemic activity of the novel cytostatic agent 
avarone and its analogues in vitro and in vivo. Cancer Res 45: 4822-4827 (1985)

11. Müller WEG, Zahn RK, Gasic MJ, Dogovic N, Maidhof A, Becker C, Diehl-Seifert B, Eich E. Avarol, a cytostatically active compound from the marine sponge Dysidea avara. Comp Biochem Physiol 80C: 47-52 (1985)

12. Müller WEG, Maidhof A, Zahn RK, Shannon WM. Effect of 9- $\beta$-D-arabinofuranosyladenine on DNA synthesis in vivo. Cancer Res 37: 2282-2290 (1977)

13. Taglialatela G, Robinson R, Perez-Polo JR. Inhibition of nuclear factor kappa B (NFkB) activity induces nerve growth factor-resistant apoptosis in PC12 cells. J Neurosci Res 47: 155-162 (1997)

14. Sachs L. Angewandte Statistik. Springer, Berlin (1974)

15. Staneck JL, Roberts GD. Simplified approach to the identification of aerobic actinomycetes by thin-layer chromatography. Appl Microbiol 28: 226-231 (1974)

16. Williams ST, Goodfellow M, Alderson G. Genus Streptomyces Waksman and Henrici 1943, 339 ${ }^{\mathrm{AL}}$. In Bergey's Manual of Systematic Bacteriology, Vol. 4. Ed.
Williams ST, et al., pp. 2452-2492, Williams \& Wilkins, Baltimore (1989)

17. Hopwood DA. Genetic contributions to understanding polyketide synthases. Chem Rev 97: 2465-2497 (1997)

18. Yenesew A, Ogur JA, Duddeck H. (R)-Prechrysophanol from Aloe graminicola. Phytochem 34: 1442-1444 (1993)

19. Kalaitzis JA, Moore BS. Heterologous biosynthesis of truncated hexaketides derived from the actinorhodin polyketide synthase. J Nat Prod 67: 1419-1422 (2004)

20. Lessmann H, Krupa J, Lackner H, Jones PG. Neue Juglomycine. Z Naturforsch 44b: 353-363 (1989)

21. Krupa J, Lessmann H, Lackner H. Ein $\alpha$ Methylanthrachinon aus Streptomyceten. Liebigs Ann Chem 1989: 699-701 (1989)

22. Fotso S, Maskey RP, Grün-Wollny I, Schulz K-P, Munk M, Laatsch H. Bhimamycin A $\sim \mathrm{E}$ and bhimanone: isolation, structure elucidation and biological activity of novel quinone antibiotics from a terrestrial streptomycete. J Antibiot 56: 931-941 (2003) 